Caligrama, Belo Horizonte, v. 24, n. 1, p. 11-32, 2019

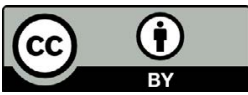

\title{
Silenciamentos de lutas em Moçambique: os jornais $O$ Africano / Brado Africano como espaços de reivindicação de cidadania ${ }^{1}$
}

\section{Silenced Struggles in Mozambique: the Newspapers O Africano / Brado Africano as Spaces of Citizenship' Claims}

\author{
Maria Paula Meneses \\ Centro de Estudos Socias da Universidade de Coimbra, Coimbra / Portugal \\ mpmeneses@gmail.com
}

Resumo: Este artigo propõe a realização de um estudo das heranças coloniais no Moçambique contemporâneo. Assente na leitura crítica de diversos arquivos culturais, o artigo procura, através de uma análise da literatura política colonial portuguesa sobre Moçambique, combinada com artigos de jornais editados na capital desta colónia no início do século XX, oferecer uma compreensão mais complexa dos encontros gerados pelo moderno colonialismo português. Esta leitura aponta pistas para uma análise mais complexa dos sentidos conceptuais de cidadania, raça, e resistência em espaço urbano, em ações políticas específicas. Em paralelo, este enfoque contribui para uma leitura mais aprofundada sobre os sentidos de ser, num contexto específico, Lourenço Marques colonial. Este enfoque sobre o espaço urbano de uma cidade colonial é particularmente interessante para uma leitura sobre o persistente silenciamento de resistências políticas que contribuíram para o fomentar de um sentimento nacional, lutas ainda ausentes do projeto nacional atual em Moçambique.

Palavras-chave: Moçambique; colonialismo; nacionalismo; lutas pela cidadania; jornalismo.

\footnotetext{
${ }^{1} \mathrm{O}$ meu agradecimento à Iolanda Vasile pelo convite para escrever para este número da revista Caligrama, por si organizado. Um agradecimento especial aos/às avaliadores/ as anónimos/as da versão inicial do texto, cuja leitura dedicada e delicada contribuiu para aprimorar o argumento.
} 
Abstract: This article aims to shed light on the colonial legacies existent in contemporary Mozambique. Based on the analysis of the Portuguese colonial political literature on Mozambique, and of newspaper articles published in the capital of this colony at the beginning of the 20th century, this article offers a more complex understanding of the cultural imprints generated by modern Portuguese colonialism. This study contributes towards a more complex analysis of the meanings of concepts such as citizenship, race, and resistance in urban context, in specific political actions. In parallel with it, this approach seeks to contribute to a more in-depth reading of the meanings of being in a specific urban context, colonial Lourenço Marques. This focus on the urban space in a colonial city is particularly interesting for a discussion on the persistent silencing of political resistance that contributed to sowing the seeds of nationalism, struggles still absent in the present nationalist project in Mozambique.

Keywords: Mozambique; colonialism; nationalism; struggles for citizenship; journalism.

\section{Introdução}

A ocupação colonial efetiva, por parte de Portugal, do território que hoje é conhecido como Moçambique acontece já na segunda metade do século XIX, estendendo-se até ao início do XX. A violenta chegada do projeto colonial-capitalista português simbolizou a incorporação política forçada deste território no espaço imperial português (MENESES, 2018). A incorporação de Moçambique no projeto político português acontece pela apropriação das terras dos africanos e pela tentativa de transformação destes em objetos, desprovidos de agência, a partir de então estudados a partir das regras e classificações científicas de cariz colonial.

Neste artigo, e privilegiando um recorte pós-colonial, combinando uma análise crítica da construção política colonial portuguesa em Moçambique com as lutas de resistências jogadas nas páginas de alguns periódicos publicados na capital desta colónia no início do século XX, procuro oferecer uma perspetiva mais complexa da ação e impacto do moderno colonialismo português. Este enfoque pós-colonial, ao incidir sobre as fissuras que estas lutas foram gerando na estrutura colonial, contribui para uma leitura mais aprofundada sobre os sentidos de ser, a partir de um contexto específico, Lourenço Marques colonial. ${ }^{2}$ Em

\footnotetext{
${ }^{2}$ Atual Maputo.
} 
paralelo, este artigo, ancorado num contexto específico, procura ampliar alguns sentidos conceptuais como cidadania, raça, espaço urbano, tanto no sentido geral quanto no decurso da ação política (MENESES, 2009).

\section{Criando espaços vazios: Moçambique como colónia de povoamento}

Para entender melhor o caráter da intervenção colonial em Moçambique, este artigo parte de uma leitura das histórias específicas sobre a criação de um lugar - Lourenço Marques -, que se tornaria a capital da colónia - e como estes processos se conectam com escalas e temporalidades mais amplas de intervenção global colonial-capitalista. A ocupação deste espaço do continente africano pelos colonizadores portugueses vai encontrar justificação na literatura colonial, quer porque o espaço a que chegavam estava vazio, ou porque quem o ocupava não o sabia explorar adequadamente (BOWEN, 2000; MENESES, 2010). A desapropriação da terra dos africanos, uma das principais funções da estrutura política e económica colonial europeia, impõe-se rapidamente nesta colónia de povoamento.

Uma das principais características do colonialismo de povoamento é a tentativa de eliminação ou silenciamento do que existe no território que se subjuga: pessoas, saberes, estruturas políticas, etc. O desejo de apropriação da terra como recurso está na origem de várias experiências de genocídio direto, deslocações forçadas e formas coercivas de assimilação cultural, social e política. Estes processos conjugados estão na origem do apropriar dos territórios autóctones como seus, sob a justificação de construção de uma nova sociedade para a população colona. No caso específico de Moçambique, o colonialismo de povoamento está na origem da emergência de uma "pequena europa", ${ }^{3}$ através da exortação de instituições e normas úteis às populações colonas que haviam migrado para a região (MENESES, 2009, 2012). E apesar da independência, laivos da herança colonial mantém-se, sendo exemplo a conservação da estrutura socio-legal sob a forma do moderno Estado-nação.

\footnotetext{
${ }^{3}$ Termo proposto por Edward Said (2000, p. 135), para descrever a transformação de "outros" territórios em "novas" versões úteis da sociedade metropolitana europeia. O resultado foi um grupo amplamente variado de pequenas Europas espalhadas pela Ásia, África e Américas, cada uma refletindo as circunstâncias, os instrumentos específicos da cultura de origem, dos projetos dos seus colonizadores.
} 
A ocupação colonial do continente africano processou-se através do reconfigurar do espaço e dos que o habitavam (i.e., a reconceptualização do território). Os portugueses, como outros colonizadores, vão renomear as terras, exigindo que os colonizados aceitassem os nomes, referências, cultura e história do conquistador (THIONG'O, 2009, p. 9). Desta forma, emergiam "novas referências" para espaços citados como vazios (de pessoas e saberes), agora preenchidos pelas referências coloniais eurocêntricas. É assim que, no caso do sul de Moçambique, o espaço urbano vai tomando o nome de Lourenço Marques (LOBATO, 1970; ZAMPARONI, 2008), uma cidade "moderna, uma cidade de África que procura não sentir a Africa" (RUFINO, 1929, p. iii). Esta apresentação da urbe colonial como referência da modernidade civilizada europeia é central para compreender as estratégias subjacentes à construção colonial do espaço, uma construção onde os lugares civilizados correspondem ao cânone urbano, modelo de uma "pequena europa" pronta para acolher os colonos que chegavam. Em paralelo, o território habitado por africanos é insistentemente qualificado como um espaço periférico, desordenado e sujo, símbolo do subdesenvolvido e de atraso. Assim, as populações colonizadas, agora ocupando "não-lugares" - espaços simbólicos forjados pela relação colonial - são transformadas em indígenas, pela virtualização do espaço. ${ }^{4}$ Esta interpretação espacial espelha a fratura abissal que ainda separa o norte global dos suis locais (SANTOS, 2007, p. 72). Este pensamento politico é epistemicamente abissal, responsável por dividir o mundo em dois lados, com as modernas teorias, supostamente universais, produzidas a partir das experiências do lado metropolitano da linha; já o outro lado da linha permanece invisível e silenciado, vistos como um vazio de saberes ou com gentes detentoras de saberes com mero valor local, tradicional. Como Boaventura de Sousa Santos destaca (2016, p. 20-21), a exclusão das realidades e experiências que aconteciam do lado colonial da linha era executada de forma a não comprometer a suposta universalidade da racionalidade científica. Neste sentido, os sujeitos que habitavam o lado colonial não contavam como seres humanos, não eram relevantes para a compreensão hegemónica moderna da humanidade.

\footnotetext{
${ }^{4}$ A partir da proposta de Marc Augé (1995, p. 77-78), é possível identificar na região de Lourenço Marques o retrabalhar colonial do sentido de espaço; ou seja, a transformação de lugares definidos relacionalmente, como raízes históricas, em não-lugares, em espaços cuja identidade permite alienar esse espaço dos contextos sociais que a constituem.
} 
Esta dicotomia - conhecimento (Europa) e ignorância (o resto do mundo) - é inerente ao projeto da modernidade, estrutural e historicamente (TROUILLOT, 2003, p. 39).

\section{Os estereótipos firmados pela presença colonial}

Uma das principais características do discurso colonial assenta na construção de imagens estáticas sobre a alteridade, representações estas que, resultado do olhar colonial, vão consubstanciar o seu projeto político. Esta inflexibilidade vai marcar a construção hierárquica da diferença entre colonos e colonizados, entre os espaços da ordem (a cidade dos brancos) e os espaços ocupados pelos negros, simbolizando a desordem e a decadência (MENESES, 2009, p. 37). Como procurarei propor, brevemente, nesta parte do texto, o não-lugar é um exercício político de criação de não-seres, a partir de categorias coloniais estáticas. É este não-lugar que ainda predomina no arquivo colonial. Como expresso por Jacques Derrida, "não há poder político sem o controle do arquivo, se não mesmo da memória. A democratização efetiva poderá sempre ser medida através deste critério essencial: a participação e o acesso ao arquivo, à sua constituição e à sua interpretação" (DERRIDA, 1995, p. 11, minha tradução).

Escrever, uma das formas de traduzir o mundo, implica, numa certa medida, revelar o que está submerso ou silenciado nos arquivos. Significa dar corpo a uma realidade que muitas vezes é sentida, apenas como latente. Os periódicos locais, especialmente os jornais $O$ Africano e Brado Africano, publicados em Lourenço Marques na primeira década do século XX, revelam como a dicotomia lugar/ não lugar é uma dicotomia dupla. Em causa, estão, concomitantemente, os espaços construídos pelo projeto colonial e os espaços vividos e experimentados pelos africanos. Se os primeiros correspondem aos "não-lugares", aos espaços simbolicamente gerados pelo projeto colonial para permitir a apropriação colonial-capitalista do espaço, os segundos têm a ver com as relações que aí acontecem. E muitas destas relações não são apreendidas pelos teóricos pós-coloniais. Por exemplo, a violência é identificada por Franz Fanon como "o estado natural” da dominação colonial (1963, p. 61), violência que resulta da perspetiva racializada que os colonos têm sobre os colonizados (incluindo representações dos colonizados como atrasados e irracionais). Como destaca Franz Fanon, 
O mundo colonizado é um mundo cindido em dois.[...] A zona habitada pelos colonizados não é complementar da zona habitada pelos colonos. Estas duas zonas se opõem, mas não em função de uma unidade superior. Regidas por uma lógica puramente aristotélica, obedecem ao principio da exclusão reciproca: não há conciliação possível [...]. A cidade do colono é uma cidade solida, toda de pedra e ferro. É uma cidade iluminada, asfaltada, onde os caixotes do lixo regurgitam de sobras desconhecidas [...]. A cidade do colono é uma cidade saciada. A cidade do colono é uma cidade de brancos, de estrangeiros.

A cidade do colonizado, ou pelo menos a cidade indígena, a cidade negra, $[\ldots]$ é um lugar mal afamado, povoado de pessoas mal afamadas. Aí se nasce não importa onde, não importa como. Morre-se não importa onde, não importa de quê. É um mundo sem intervalos, onde os homens estão uns sobre os outros, as casas umas sobre as outras.

A cidade do colonizado é uma cidade faminta, faminta de pão, de carne, de sapatos, de carvão, de luz. (1963, p. 37-39)

É esta “desumanização" abissal que transforma o sujeito, que vive no espaço colonial, num ser sub-humano (FANON, 1963, p. 42). Todavia, a esta leitura, assente numa relação dicotómica, escapam as posições dos que, como vários dos articulistas da imprensa da época, vão cruzando a linha abissal. Este trespassar do lugar fixo está refletido em suas colunas de opinião sobre as novas zonas transculturais que estavam a ser produzidas nas zonas de contato entre colonizadores e colonizados. Em linha com a argumentação de Robert Young (1995, p. 163), o exame destes textos de imprensa, escritos durante a implantação do colonialismo moderno, revela que se trata de algo mais do que documentos. Estes textos espelham a produção de conhecimento sobre a alteridade, e a forma em como estas identidades foram sendo negociadas e (re)constituídas, para além da perspetiva fixada na documentação produzida pelo Estado colonial.

Até à realização da conferência de Berlim (1884-1885), onde as potencias colonizadoras irão "partilhar" a África entre si, eram várias as formas de penetração colonial europeia no continente. A chegada da moderna colonização de ocupação aos territórios da África oriental vai ficar marcada, por um lado, pelas disputas territoriais de Portugal, Inglaterra, Alemanha e França, que procuravam alargar as suas influências a territórios vistos como potenciais mercados e fontes de recursos humanos e materiais. Portugal, que até então arvorava o "direito histórico" para 
justificar a posse de territórios na região (MARQUES, 1998, p. 166-168), vai ser obrigado a "ocupar" fisicamente os territórios que reclamava "seus", para provar a sua presença colonizadora efetiva. Como resultado, até finais da Primeira Guerra Mundial, a história colonial de Moçambique é marcada por várias revoltas, ações de resistência às manobras militares de conquistas usadas para subjugar as sociedades africanas (SERRA, 2000; PÉLISSIER, 2000, p. 171-172). Associada a estas campanhas militares acontece a instalação do aparelho administrativo colonial português, por forma a completar a formação da "colónia de Moçambique". Especial destaque no estabelecimento da moderna administração do Estado colonial coube a António Ennes e seus correligionários. ${ }^{5} \mathrm{~A}$ eles se devem muitos dos códigos legais que vão legitimar a função colonial de Portugal e criar a figura do "indígena" enquanto outro racialmente inferior. ${ }^{6}$ Neste contexto, destaca-se o Regulamento do Trabalho Indígena, ${ }^{7}$ o qual introduz a obrigatoriedade do trabalho para os "indígenas" africanos (MENESES, 2010, p. 76), como forma de obter "os meios que thes faltassem para substituir e melhorar a própria condição social" (art. 1). Outro instrumento legal fundamental foi a Lei da Administração Civil das Províncias Ultramarinas ${ }^{8}$ que legitimou a separação jurídica entre os indígenas e os outros habitantes do espaço colonial.

Como Eduardo da Costa - da geração de António Ennes - sublinhou em vários momentos, as colónias portuguesas só eram económica e legalmente administradas através da presença de uma conceção abissal do direito e da cidadania: "é preciso, nas nossas possessões, a existência de, pelo menos, dois estatutos civis e políticos: um europeu e outro indígena. Não quer isto dizer que seja interdito a todos os indígenas o estatuto europeu, mais isso depende da sua instrução e dos seus hábitos" (COSTA, 1901, p. 590). A separação hierárquica racial e a consagração formal da inferioridade jurídica do indígena e do seu estatuto de nãocidadão acontece com o Estatuto do Indigenato, já em 1926. ${ }^{\circ}$ De acordo

\footnotetext{
${ }^{5}$ Veja-se, entre outros, Ennes (1971) e Albuquerque (1935).

${ }^{6}$ Em vária dos códigos legais da altura (ex. Regulamento de Importação, Vendas, Uso e Licença de Armas de Fogo de 1914), o indígena é caracterizado quer como descendente de pais indígenas, de "raças africanas", quer pelas suas características físicas.

${ }^{7}$ Diário do Governo n ${ }^{\circ} 262$, de 18 de novembro de 1899.

${ }^{8}$ Diário do Governo $\mathrm{n}^{\circ}$ 143, de 15 de agosto de 1914.

${ }^{9}$ Estatuto Político, Civil e Criminal dos Indígenas de Angola e Moçambique, Decreto $\mathrm{n}^{\circ}$ 12.533 , de 23 de outubro. De acordo com este, consideravam-se indígenas "os indivíduos
} 
com o direito colonial português, os indígenas eram apenas "súbditos portugueses", submetidos à proteção do Estado, mas sem fazerem parte da Nação. A Nação, interpretada como comunidade cultural e como associação política dos cidadãos, estava interditada aos indígenas, visto faltarem-lhe os requisitos de assimilação de cultura e por não terem ainda conquistado a cidadania (CAETANO, 1957, p. 23). O Estatuto vai consagrar a criação do indígena como invisível e sem voz, fruto de uma injustiça epistémica, que com o tempo, se consolidou como representação simplificada e fixa da modernidade eurocêntrica, insensível à diversidade cultural, às diferentes formas de ser e saber que ocupavam o espaço colonizado (BHABHA, 1983, p. 18).

O conjunto de códigos legais que fundamentam a implantação de uma separação abissal entre os que são e os que não-são foram fundamentais para a administração portuguesa criar a categoria do indígena, tutelado pelo Estado colonial. ${ }^{10}$ Estes elementos jurídicos fundacionais da política colonial portuguesa para Moçambique não só repudiavam a liberdade e a igualdade entre colonos e colonizados, como introduziram uma separação jurídica abissal entre colonizadores (julgados pelos códigos vigentes na metrópole) e os colonizados, sem direitos, e que se encontravam sob a tutela portuguesa. Entre estas duas categorias opostas funcionava ainda uma outra - a dos assimilados (MENESES, 2010, p. 85). Como estabelecido no Estatuto (art. 56), os assimilados eram os indígenas que haviam adquirido o estatuto de cidadão português após provarem satisfazer cumulativamente vários requisitos, entre os quais falar corretamente a língua portuguesa; exercer uma profissão que garantisse rendimento necessário para o sustento próprio e da família a seu cargo, ou possuir bens suficientes para o mesmo fim; ter bom comportamento; ter a educação e hábitos pressupostos para a integral aplicação do direito público e privado dos cidadãos portugueses, etc.

de raça negra ou seus descendentes que, tendo nascido ou vivendo habitualmente [nas colónias], não [possuíssem] ainda a ilustração e os hábitos individuais e sociais pressupostos para a integral aplicação do direito público e privado dos cidadãos portugueses" (artigo $2^{\circ}$ ). Este Estatuto, que conheceu várias reformulações, foi uma das principais peças jurídicas que garantiu a existência de direitos políticos e sociais diferenciados para os africanos da Guiné, de Angola e de Moçambique. Foi formalmente abolido em setembro de 1961.

${ }^{10}$ Esta estrutura segregacionista vai se consagrar através do Regulamento do Trabalho Indígena (Decreto $\mathrm{n}^{\circ}$ 951, de 14 de outubro de 1914). 
No contexto de Moçambique, o projeto colonial inscreveu uma forma de governamentalidade informada por uma relação perversa entre o conhecimento "científico" e o exercício de poder. "Conhecer" as populações indígenas através das lentes coloniais, hierárquicas, legitimou a presença de formas discriminatórias e autoritárias de controle político, ao mesmo tempo que enclausurou a população colonizada num sistema de representações que, apoiado no argumento da ciência moderna, justificava o atraso dos africanos como causa e efeito desta situação. Os textos que se analisam em seguida, das primeiras décadas do seculo XX, ao questionar a construção do conhecimento colonial e das opções que este conhecimento oferecia, instigam ao estudo de vários agentes produtores de saber, incluindo a agência do próprio arquivo colonial como produtora de conhecimento (STOLER, 2002). Exemplo de um saber gerado numa zona transcultural, a leitura dos contactos é politizada por estes articulistas, os quais debatem, de forma subversiva, o poder ideológico colonial que acentua a divisão e a separação. É aqui que reside o potencial de resistência destes textos, que desafiam as estruturas de dominação em criação, a partir, também, do saber colonial, que os autores assimilados desta imprensa dominam.

\section{Desafios para penetrar na cidadania: $O$ Africano e o Brado Africano em Lourenço Marques}

As tentativas de tornar o africano local num não-lugar, descaracterizando-o e despersonalizando-o são centrais às ontologias e processos colonias-capitalistas. As histórias e representações dominantes sobre a diferença cultural em espaços coloniais apenas permitem que o africano exista como um corpo negro, negando-lhe qualquer capacidade de iniciativa e saber. Eliminando liminarmente qualquer possibilidade de negociação de sentidos de ser e de saber entre colonizados e colonizadores, esta ideologia colonial racial é responsável pela introdução do "africano como negro" nos discursos coloniais, um corpo racializado, cuja identidade como atraso é fixada a partir de fora, pelas forças colonizadoras (FANON, 1963). Neste sentido, é fundamental examinar a construção geo-histórica do lugar, através de uma leitura atenta e cuidadosa do espaço-tempo e das narrativas que o caracterizam, elementos que são, eles próprios, fundamentais à (pré)ocupação geográfica espelha como o projeto de diferenciação racial, associado ao mito da pureza e superioridade cultural europeia, deu origem a vários estereótipos coloniais. No caso de 
Moçambique, aqui analisado, os estereótipos permitiram "normalizar" a diversidade de sujeitos que integram as representações coloniais dominantes como se se tratassem de um corpus único; esta representação dominante separou os africanos dos seus lugares, das suas relações, introduzindo-os nas referências modernas dominantes através das imagens presentes no discurso colonial, desafiando qualquer forma de protesto.

O território atual de Moçambique no final do século XIX conheceu, em vários momentos, o esvaziar a terra dos seus ocupantes e das relações sociais e simbólicas que os uniam ao território. A ressignificação do território como espaço europeu - Lourenço Marques -, e não africano, foi um dispositivo central para transformar este espaço numa colónia de povoamento, como já referido, disponível para os fluxos de colonos que vinham desenvolver capitalisticamente a colónia. Nas margens da cidade branca, porém, em zonas de contato geradas pelo violento encontro colonial, sentia-se a pulsão das pequenas vozes que protestam e desafiam a opressão colonial. Neste sentido, em alternativa, proponho uma leitura do processo de criação de espaço colonial onde, apesar de as violências de desapropriação, transformações físicas radicais e tentativas de ocupação pela renomeação do lugar, é possível identificar brechas na estrutura colonial. Através destas, de forma capilar é possível escutar outras vozes e outras formas de reivindicação cidadã, mais além da proposta do sistema colonial, revelando a inalienabilidade de Lourenço Marques, da sua população africana, do seu "Xilunguíni”."

$\mathrm{O}$ Estatuto do Indigenato, acima referido, gerou renovados protestos da pequena burguesia local (PENVENNE, 1989; ZAMPARONI, 2008), na medida em que estabelecia, em contrapelo às peças legislativas anteriores, muitas editadas localmente, uma série de exigências que deviam ser cumpridas para que qualquer indivíduo não europeu (ou não asiático) deixasse de ser considerado legalmente indígena e passasse a ser considerado assimilado. A identificação de assimilado era garantida pela posse de um alvará, prova da "ascensão" ao novo estatuto de cidadão, separado do tratamento reservado aos indígenas.

Para a ideologia colonial, o estatuto de assimilado era visto como a consagração da civilização, o ultrapassar, pelo assimilar dos valores europeus, do "atraso" secular dos indígenas. Neste contexto de opressão,

\footnotetext{
${ }^{11}$ Termo que descrevia a cidade habitada primordialmente por brancos, onde se falava português (LOBATO, 1970).
} 
são particularmente expressivas a sabedoria e a coragem daqueles que lutaram por justiça, pelos direitos civis dos africanos (BRAGA-PINTO; MENDONÇA, 2014).

Os jornais aqui estudados - O Africano e o Brado Africano - vão constituir-se como um espaço de congregação de vozes de protesto de assimilados (PENVENNE, 1989; ROCHA, 2002) em Lourenço Marques, posicionando-se contra a situação colonial. Uma leitura detalhada dos escritos deixados por estes atores políticos permite conhecer um dos momentos fundacionais do nacionalismo moderno em Moçambique. Estes atores, expondo os atentados à condição de vida dos africanos e os "podres" da politica civilizadora nas páginas destes jornais, procuraram mudar os termos em que a política era discutida - para repensar os significados do sentido de pertença e formas de ação política.

A crescente chegada de colonos brancos, maioritariamente oriundos de Portugal, vai resultar numa discriminação legalizada (escalões diferenciados na função pública, novas disposições sobre definição de "assimilado"). Para a administração colonial, a cor era o elemento que agora estruturava a hierarquia entre os filhos da terra e os colonos metropolitanos, num contexto em que muitos dos assimilados possuíam qualificações iguais ou superiores às dos colonos. Uma descrição de 1913 é paradigmática quanto à representação do agente da colonização do branco:

N'um casebre escuro e malcheiroso, um balcão sebento, alguns barris do tal, latas de sardinha, bancos escuros, moscas voejando e... lixo, muito lixo. Para lá do balcão, um ser cabeludo e barbado mexe-se com alguma dificuldade, dando aqui e além um olhar distraído à sordidez das coisas que lhe garantem a ele a bemaventurança, o bago, a massa. É o mulungu [branco]; é a alma gentil da colonização (ALBASINI, 1913, p. 3).

O revelar da violenta discriminação racial que atingia os indígenas e assimilados de Moçambique repetir-se-á nestes jornais. Não admira o grito anónimo de impotência e de revolta contra a prepotência colonial: "muito custa a gente nascer preto!" (MANHIÇA, 1915, p. 2). O logro das promessas de equidade, liberdade e justiça ecoa pelas páginas destes jornais.

Somos apenas negros. [...] Defendemos a nossa terra; e a única política que nos importa é a da nossa terra propriamente dita. [...] 
A África nada ganhou com o regime [republicano] e o africano, esse talvez perdesse, pois nunca o privilégio das castas foi tão alto como n'esta era democrática (ALBASINI, 1911, p. 1).

Cidadãos de segunda, os assimilados apercebiam-se da transformação política em curso, que lhe atribuía uma categoria inferior face ao branco, europeu. A defesa da causa negra e indígena, contra a exploração e discriminação, foi abraçada por muitos dos assimilados. A denúncia da "caça ao indígena", obrigado a pagar a chapa que o identificava como trabalhador e que se envenenava com o "vinho colonial", vão ser apontadas ao governo colonial, expondo-se a exploração brutal do africano, e não o progresso tão apregoado pelo governo colonial:

O Estado [...] mantém a sua atitude nobre e digna: numa mão a espada que pune e noutra ... o vinho colonial que faz esquecer o sofrimento. O que quer dos negros é simplesmente o dinheiro da palhota, os sete dias de trabalho gratuito [...] e que tenham a capacidade estomacal de tragar grandes doses do dito [vinho] colonial (ALBASINI, 1914, p. 3).

A "missão civilizadora" de Portugal em Moçambique vai ser repetidamente questionada nas páginas destes jornais: "[Depois] de vexar os indígenas, exigindo-lhes passes e alvarás de assimilados; [...] depois de roubar-lhes o gado, etc., etc., etc., poderá Portugal dizer que veio para a África para civilizar?” (AVANTE, 1924, p. 2).

Uma leitura detalhada destes jornais identifica vários artigos que expõem os vícios da presença colonial-capitalista em Moçambique: o imposto de palhota, o trabalho forçado, o vinho colonial, entre outros, obrigatórios para os indígenas, instrumentos que asseguravam a manutenção dos privilégios dos colonos.

Um grupo humilde - de triste humildade dos homens de cor - pretende, anseia, quer fundar n'esta cidade, uma escola de instrução primária [...] Há muitos centos de anos já, que aceitamos um jugo dos que julgamos civilizadores. [...] Temos reagido contra os abusos, nada mais. É verdade que um pouco violentamente, mas sempre escudados pela razão. [...] Em troca d'esta submissão, que causa pasmo no estrangeiro, que temos nós? Nada! Nem estradas, nem pontes, nem oficinas, nem escolas! Temos - para que a raça mais depressa pereça, se desfaleça no esquecimento do túmulo - o vinho branco para pretos e liberdade plena, pleníssima, 
incontestável, de tomarmos bebedeiras abomináveis irmãs da demência, com essa infamíssima mixórdia que todos os paquetes despejam n'esta desgraçada terra de Deus! [...]

O preto não duvida da excelência da nossa escola, ponto é que a gente o convença. É agora, aqui neste ponto que convidamos os civilizadores a reverem-se na sua obra... Os súbitos de S.M. o Rei de Portugal não falam o português! - E dura este domínio há mais de 400 anos!... (ANO..., 1908, p. 1)

Reivindicando-se de "negros portugueses" ou de "africanos portugueses", de cidadãos de pleno direito, estes assimilados foram tomando consciência da sua condição de colonizados e explorados, num percurso repleto de contradições e ambiguidades. Estes textos afirmam uma forma diferente de resistência, localizando-a nas práticas jornalísticas subversivas, possíveis ainda nesta etapa colonial, enfraquecendo, assim, a base sobre a qual os projetos coloniais produziam as suas reivindicações de superioridade.

Em 1920, no Brado Africano questionavam-se quais os benefícios para os africanos das políticas de desenvolvimento colonial:

É uma utopia pensar-se que se possa desenvolver as colónias conservando o nativo no seu estado primitivo, como besta de carga, como criança grande que não convém desenvolver-lhe a inteligência. Se se quer viver como potência colonial de valor, a instrução tem de ser difundida sem limites, entre os naturais, tornando-se a nação credora de respeito e admiração. [...] Melhor viver teríamos se as possibilidades das nossas colónias fossem desenvolvidas por elementos nacionais, numa união de forças entre os portugueses metropolitanos e coloniais, como elementos componentes do levantamento moral e material da nacionalidade portuguesa, da pátria comum de Portugal (O PROBLEMA..., 1920, p. 3).

A afirmação da portugalidade vai marcar parte desta luta, defendendo estes assimilados um projeto específico, com diferentes níveis de pertença política a Moçambique, expandindo a ideia de um conjunto político "luso-africano":

É da nossa obrigação, como já civilizados, trabalhar ativamente para que nenhum africano preto ou mulato deixe de frequentar a escola até saber ler, escrever e contar em português. Nós somos 
portugueses. [...] O indígena português que não sabe ler e escrever português está fora da civilização. Não pode pedir que o tratem como civilizado (O ENSINO... 1923, p. 3).

Defensores da emancipação dos "negros portugueses" de Moçambique, estes assimilados vão ver na educação, e no uso da língua portuguesa, um motor de ascensão à civilização. Desde cedo apelaram a todos os negros para que estudassem em português, para que se elevasse o conceito que os colonos tinham sobre eles, "para alcançarem direitos e regalias iguais aos dos [...] compatriotas brancos" (O ENSINO, 1909, p. 3). Por outro lado, vão expor as situações de discriminação racial e de sexismo que aconteciam a par e passo na cidade. Em 1911, um artigo protestava o facto de "mulheres decentemente vestidas com capulanas asseadíssimas" serem obrigadas a viajar de pé, nas traseiras dos elétricos, embora pagassem um bilhete de igual valor ao dos restantes passageiros brancos (OS ELÉTRICOS, 1911, p. 2). Alguns anos depois, o assunto é retomado, com o articulista a insurgir-se, de novo, contra situações de discriminação:

[...] estimaria imenso que V. Exa mandasse por um aviso para os pretos saberem onde se devem sentar. Tenho vistos nos carros brancos sujos sentados dentro, ao passo que alguns africanos decentes e bem vestidos e civilizados como eu, são obrigados a sentar Deus sabe onde" (BAKAR, 1928, p. 3).

Foi o estatuto perifericamente privilegiado que o grupo de jornalistas assimilados possuía - operando numa zona transcultural de contactos na sociedade colonial - que lhes permitiu conhecer por dentro os vícios de uma sociedade que se propunha dividida entre brancos e negros, colonizadores e colonizados. Expondo a violência fruto da perspetiva racializada e discriminatória que os colonos detinham sobre os colonizados, vão defender uma outra forma de pertença, forjada no cruzamento de saberes e culturas.

Estas distinções de cores; entre os da mesma raça (porque a cor nada influi nas seleções que os Europeus nos fazem, bastando que eles saibam a origem para ser considerado - e com justa razão - um negro, por nas suas veias correr o sangue africano) têm causado um prejuízo à nossa África, porque enquanto nós altercamos - entre nós mesmos, em vez de consolidarmos as nossas ideias, unindo-nos - unia a perfeita Torre de Babel - os 
europeus vão-se aproveitando das nossas confusões, rindo-se à socapa destas discórdias de baixos sentimentos, querendo afastar de nós o nativo menos culto ou de cor mais negra do que a nossa, - por simples vaidade, e vão desprezando-nos a ponto de não nos quererem instruir (AS CORES, 1924, p. 1).

Esta e outras colunas vão denunciar a "desumanização" colonial que insistia em fraturar abissalmente os que habitavam Lourenço Marques, ao transformar o sujeito colonial num sub-humano. Como Franz Fanon sublinhou, em situação colonial, a base económica também se traduz em dominação política e cultural: "é-se rico porque se é branco, e é-se branco porque se é rico" (1963, p. 40). Num contexto de crescente opressão, os moçambicanos resistiram, assegurando agência suficiente para denunciar a violência colonial, reivindicando outras formas de progresso, outras ações e iniciativas. Este foi um dos méritos importantes da pequena camada de assimilados, antes da chegada ao poder do regime do Estado Novo. ${ }^{12}$ E é nesta altura que estes assimilados assumem que o papel que tinham pretendido desempenhar, de intermediários entre os colonizadores portugueses e os indígenas, e que qualquer convergência e progressão transcultural gradual, era impossível para o projeto colonial. "Têm medo que nos tornemos independentes, que conheçamos os nossos direitos", afirmava um dos articulistas do Brado Africano (NETTO, 1932, p. 2). Afinal, a política colonial revelava-se servir interesses muito específicos:

[...] conservar o nativo na sua ignorância primitiva, para que o negro só sirva para trabalhos manuais debaixo do jugo dos brancos, analfabetos que sejam, para que estes possam dar honradamente a sua vergastada de cavalo-marinho, se o preto não tira o chapéu ou se levanta quando ele passa (INSTRUÇ̃̃̃..., 2).

\section{Conclusão: lutas e experiências que contribuem para uma reflexão crítica sobre o ser e a emancipação}

Os editoriais e colunas publicados nos jornais $O$ Africano e o Brado Africano revelam uma intensa movimentação de pessoas entre

\footnotetext{
${ }^{12}$ A chegada ao poder de um regime colonial fascista trouxe consigo uma limitação apertada da liberdade de imprensa, quer na metrópole, quer em contextos coloniais (RIBEIRO; SOPA, 1996).
} 
lugares, uma realidade que importa explorar no presente, como forma de desestabilizar as dualidades exclusivistas impostas pela modernidade eurocêntrica colonial: centro-periferia; civilizado - selvagem; moderno - tradicional; etc. Dando eco ao desafio de Couze Venn (2006, p 1), a leitura destes periódicos permite ouvir outras vozes que procuraram desafiar o binarismo colonizador-colonizado, revelando um conjunto de texto que espelham uma reflexão crítica às múltiplas narrativas de ser e emancipação no espaço colonial de Moçambique.

Como este artigo procura revelar, os não-lugares, os lugares alienados são produzidos - geográfica e discursivamente - através de processos de conflito ou resistência, cuja história importa resgatar. Ao resgatar outras vozes o "momento presente" destaca-se como um epifenómeno resultante de processos sociais e materiais anteriores, permitindo deste modo, restaurar a agência de classes sociais conflituantes, ao invés de entender as suas ações como inteiramente super-determinadas pela lógica colonial.

Escrevendo sobre as fronteiras culturais, Edouard Glissant identifica-as não como "fatores do impossível, mas como lugares de passagem e transformação" (2006, p. 16). Uma análise cuidadosa dos periódicos $O$ Africano / Brado Africano, publicados no início do século XX em Lourenço Marques, fornecem uma perspetiva própria sobre a construção da cidadania em Moçambique. Neste caso, esta análise centrase na interpretação e interpelação da experiencia do colonialismo como intervenção política e intelectual.

Para os portugueses que chegavam a Moçambique, a partilha de território, das suas culturas e leis era uma impossibilidade derivada da natureza da missão colonizadora, apresentada como

a ação exercida por um povo civilizado sobre um país de civilização inferior, com o fim de o transformar progressivamente, pelo aproveitamento dos seus recursos naturais e pelo melhoramento das condições materiais e morais da existência indígena (MARNOCO E SOUSA, 1906, p. 8).

Em desafio a esta violência, os vários textos aqui trazidos apontam a importância de analisar as resistências geradas com a imposição do projeto colonial moderno, no contexto do espaço-tempo em que se situam, um espaço tempo mediado hegemonicamente por um pensamento abissal que procura desarticular a "nação civilizada" do "indígena" (SANTOS, 
2007; MENESES, 2009). Porém, como esta análise centrada na penetração colonial portuguesa em Moçambique, expõe, os intelectuais nacionalistas, oriundos do ambiente "assimilado", desafiaram as noções de identidades raciais fixas nas páginas dos jornais, tentando simultaneamente formular ideias mais humanizadoras sobre quem somos como indivíduos, como parte de comunidades mais amplas. Por isso é tão importante combinar uma crítica da desunião colonial com a apresentação de momentos criativos sobre a gestação da moçambicanidade.

As colunas e os editoriais guardados nos periódicos aqui analisados oferecem uma imagem poderosa de luta e de construção de um sentimento nacional de pertença. Esta luta de resistência encontra eco em vários acontecimentos históricos recentes no país, em termos de ativismo político e jornalístico. Contextualizadas pelos projetos sociojurídicos coloniais que legitimavam e ancoravam a ação colonial civilizadora de Portugal, estas colunas e editoriais expõem uma das fases mais críticas da imposição do colonialismo moderno, que trouxe consigo a limitação ao desenvolvimento da imprensa e dos direitos dos "súbditos coloniais". Inúmeras peças jornalísticas contribuíram para dar visibilidade a uma crescente ideia de Moçambique, um território de disputas identitárias onde os jornalistas, assimilados, reivindicavam o fim das leis da assimilação, da discriminação racial, do trabalho forçado e da expropriação de territórios, condição para que os africanos tivessem direitos civis (BRAGA-PINTO; MENDONÇA, 2014, p. 42-43). O escrutínio destas peças espelha indagações críticas a temas como a educação indígena, o transporte público, o financiamento dos projetos coloniais, questionandose igualmente a expansão do espaço urbano colonial e do bem-estar das populações colonizadoras à custa de moradores locais, não-brancos. A crítica à questão racial atravessa muito do material analisado, exemplo de uma resistência ao colonialismo, a partir de uma avaliação crítica de um sistema violento que prometia uma mudança civilizadora. Este ativismo político jornalístico, exercido por assimilados na viragem para o século XX, vai servir de base ao desenvolvimento de uma imprensa de protesto e resistência em Moçambique (PENVENNE, 1989; RIBEIRO; SOPA, 1996). As peças jornalísticas que vão ser publicadas em Lourenço Marques neste período contribuíram para esclarecer o novo contexto político, fornecendo pistas que ajudavam os autores das colunas de opinião e editoriais, e os seus leitores, a confrontar e a adaptar o pensamento político e sociocultural europeu que se impunha. Espelhando 
as lutas vividas numa cidade colonial, a análise sugere um Moçambique parte de um mundo globalizado, partilhando eventos que não estavam muito distantes do que acontecia noutros contextos do mundo.

A leitura destes materiais ajuda a densificar a narrativa de resistências à penetração colonial. Aqui importa identificar as conexões entre o desenvolvimento de resistências à imposição do domínio colonial, que Terence Ranger (1968) definiu como "resistência primária", e as lutas dos modernos movimentos nacionalistas, que o mesmo autor descreveu como "resistência secundária". Esta abordagem permite situar os processos históricos com mais detalhe, o que permite para entender as motivações para a luta nos termos dos agentes que a concretizam, expondo claramente os tempos e os lugares em que os processos políticos ocorreram. Ao mesmo tempo, para que as respostas façam sentido, é preciso reconhecer que nada estava imune a mudanças. Um dos problemas com os termos resistência e colaboração é que eles sugerem que as comunidades adotavam uma ou outra postura, de uma forma estática. Mas, ao longo da história, as pessoas realizaram alianças estratégicas - às vezes com os opressores alterando as formas de resistência ou de colaboração ao longo do tempo. Uma abordagem simplificada e estática, que por vezes, parece transparecer de análises dicotómicas generalizantes sobre a resistência africana ao colonialismo, espelha a impossibilidade de reconhecimento da agência e do conhecimento de quem estava envolvido nas lutas emancipatórias no início de século em Moçambique. Por outro lado, insistir apenas numa única narrativa que une todos os momentos de resistência em um só projeto nacionalista, como os modernos partidos em Moçambique sustentam (MENESES, 2015), não só traz o risco de anacronismo, mas também separa os conflitos e as possíveis alianças entre forças distintas.

Sem uma compreensão mais profunda do ethos intelectual do colonizado não é possível compreender os processos de libertação e as lutas pela descolonização em Moçambique e no continente. Nestes jornais, os debates suscitados estabeleceram as bases ideológicas para a emergência, em Moçambique, de um projeto nacional democrático, que reconhece que, como cidadãos, os moçambicanos são um só povo, apesar de, como indivíduos exibirem formas distintas de ser e de se identificarem. Assumir-se como moçambicano significa, pois, ter liberdade para rejeitar as antigas classificações coloniais (e as iniquidades e desigualdades associadas), por um lado, e, por outro, para pensar sobre o que há de comum, validando-se e respeitando-se as diferenças que não assentes na 
injustiça económica e cognitiva. O reconhecer da presença, escondida em arquivos, de vozes plurais de sujeitos e movimentos africanos assinala a presença de uma consciência política cidadã sobre a situação experimentada. E é esta humanidade reflexiva, parte do legado das lutas de resistência, que importa regatar dos arquivos.

Agradecimentos: Na origem deste artigo estão vários projetos de investigação, especialmente o BLEND (com apoio do FEDER através do Programa Operacional Competitividade e Inovação COMPETE 2020) cujo financiamento PTDC / CVI-ANT / 6100/2014 - POCI-01-0145FEDER-016859 está na origem de parte da pesquisa aqui apresentada.

\section{Referências}

ALBASINI, J. Amor e Vinho (idílio pagão). O Africano, Lourenço Marques, p. 3, 11 jun. 1913.

ALBASINI, J. No Aniversário da República. O Africano, Lourenço Marques, p. 1, 30 set. 1911.

ALBASINI, J. O Vinho para o Preto. O Africano, Lourenço Marques, p. 3, 10 jun. 1914.

ALBUQUERQUE, J. M. Livro das Campanhas. Lisboa: Agência Geral das Colónias, 1935.

ANO Novo - Era Nova. O Africano, Lourenço Marques, p. 1, 25 dez. 1908.

AS CORES. Brado Africano, Lourenço Marques, p. 1, 9 set. 1924.

AUGÉ, M. Non-Places: Introduction to an Anthropology of Supermodernity. London: Verso, 1995.

AVANTE. Brado Africano, Lourenço Marques, p. 2, 23 set. 1924.

BAKAR, Z. Os Elétricos. Brado Africano, Lourenço Marques, p. 3, 24 nov. 1928.

BHABHA, H. K. The Other Question... Screen, [S.l.], v. 24, n. 6, p. 1836, 1983.

BOWEN, M. L. The State Against the Peasantry: Rural struggles in colonial and postcolonial Mozambique. Charlottesville, VA: University Press of Virginia, 2000. 
BRAGA-PINTO, C.; MENDONÇA, F. (org.). João Albasini e as luzes de nwandzenguele: literatura e política em moçambique 1908-1922. Maputo: Alcance Editores, 2014.

CAEtano, M. A Constituição de 1933: Estudo de Direito Político. Coimbra: Coimbra Editora, 1957.

COSTA, E. A. Estudo sobre a Administração Civil nas nossas Possessões Africanas. Boletim da Sociedade de Geografia de Lisboa, Lisboa, v. 7-12, p. 535-761, 1901.

DERRIDA, J. Archive Fever: A Freudian Impression. Tradução de Eric Prenowitz. Diacritics, Baltimore, v. 25, n. 2, p. 9-63, 1995. DOI: https:// doi.org/10.2307/465144.

ENNES, A. Moçambique: Relatório apresentado ao governo. 4. ed. Lisboa: Agência Geral do Ultramar, 1971.

FANON, F. The Wretched of the Earth. New York: Grove Press, 1963.

GLISSANT, E. Il n'est frontière qu'on n'outrepasse. Le Monde diplomatique, Paris, p. 16-17, out. 2006.

INSTRUÇÃO Indígena. Brado Africano, Lourenço Marques, p. 2, 16 fev. 1924.

LOBATO, A. Lourenço Marques, Xilunguíne: Biografia da Cidade. Lisboa: Agência Geral do Ultramar, 1970.

MANHIÇA, F. O Africano, Lourenço Marques, p. 2, 3 jul. 1915.

MARNOCO E SOUSA, A. Administração Colonial. Coimbra: Tipografia França Amado, 1906.

MARQUES, A. H. O. Nova História da Expansão Portuguesa: O Império Africano (1890-1930). Lisboa: Estampa, 1998, p. 166-168. (v. XI). DOI: https://doi.org/10.14195/0870-4147_32_1.

MENESES, M. P. 'Xiconhoca, o inimigo': Narrativas de violência sobre a construção da nação em Moçambique. Revista Crítica de Ciências Sociais, Coimbra, v. 106, p. 9-52, 2015. DOI: https://doi.org/10.4000/ recs.5869.

MENESES, M. P. Colonialismo como violência: a 'missão civilizadora' de Portugal em Moçambique. Revista Crítica de Ciências Sociais, Coimbra, Número especial, p. 115-140, 2018. 
MENESES, M. P. Images Outside the Mirror? Mozambique and Portugal in World History. Human Architecture, Boston, v. 10, n. 1, p. 121-137, 2012.

MENESES, M. P. O 'Indígena' Africano e o Colono 'Europeu': a construção da diferença por processos legais. E-cadernos CES, Coimbra, v. 7, p. 68-93, 2010. DOI: https://doi.org/10.4000/eces.403.

MENESES, M. P. Poderes, Direitos e Cidadania: O 'retorno' das autoridades tradicionais em Moçambique. Revista Crítica de Ciências Sociais, Coimbra, v. 87, p. 9-42, 2009. DOI: https://doi.org/10.4000/ recs. 1428.

NETTO, J. As Escolas para Africanos. Brado Africano, Lourenço Marques, p. 2, 14 mai. 1932.

O ENSINO para o Indígena. Brado Africano, Lourenço Marques, p. 3, 17 mai. 1923.

O ENSINO. O Africano, Lourenço Marques, p. 3, 1 mar. 1909.

O PROBLEMA da Instrução. Brado Africano, Lourenço Marques, p. 3, 8 nov. 1920.

OS ELÉTRICOS. O Africano, Lourenço Marques, p. 2, 30 set. 1911.

PÉLISSIER, R. História de Moçambique. Formação e oposição: 18541918. Lisboa: Estampa, 2000. (vol. I).

PENVENNE, J. 'We are all Portuguese!' Challenging the Political Economy of Assimilation: Lourenço Marques, 1870-1933. In: VAIL, L. (org.). The Creation of Tribalism in Southern Africa. Berkeley: University of California Press, 1989. p. 256-281.

RANGER, T. Connexions between 'Primary Resistance Movements' and Modern Mass Nationalism in East and Central Africa. Journal of African History, Cambridge, v. 9, n. 3, p. 437-453; v. 9, n. 4, p. 631-641, 1968.

RIBEIRO, F.; SOPA, A. (org.). 140 Anos de Imprensa em Moçambique. Maputo: Associação Moçambicana da Língua Portuguesa, 1996.

ROCHA, A. Associativismo e Nativismo em Moçambique: contribuição para o estudo das origens do nacionalismo moçambicano (1900-1940). Maputo: Promédia, 2002. 
RUFINO, J. S. Álbuns fotográficos e descritivos da Colónia de Moçambique: Lourenço Marques - Panoramas da Cidade. Hamburgo: Broschek \& Co, 1929. (v. III).

SAID, E. The Edward Said Reader. New York: Vintage Books, 2000.

SANTOS, B. S. Epistemologies of the South and the Future. From the European South, Padova, v.1, p. 17-29, 2016.

SANTOS, B. S. Para além do pensamento abissal: das linhas globais a uma ecologia de saber. Novos Estudos CEBRAP, São Paulo, v. 79, p. 71-94, 2007. DOI: https://doi.org/10.1590/S0101-33002007000300004.

SERRA, C. História de Moçambique. Maputo: Imprensa Universitária, 2000. (v. I).

STOLER, A. L. Colonial Archives and the Arts of Governance. Archival Science, [S.1.], v. 2, p. 87-109, 2002. DOI: https://doi.org/10.1007/ BF02435632.

THIONG'O, N. Something Thorn and New: an African Renaissance. New York: Basic Civitas Books, 2009.

TROUILLOT, M.-R. Global Transformations: Anthropology and the modern world. New York: Palgrave Macmillan, 2003. DOI: https://doi. org/10.1007/978-1-137-04144-9.

VENN, C. The Postcolonial Challenge: Towards alternative worlds. London: Sage, 2006.

YOUNG, R. J. C. Colonial desire. Hybridity in theory, culture and race. New York: Routledge, 1995.

ZAMPARONI, V. Colonialism and the Creation of Racial Identities in Lourenço Marques, Mozambique. In: BARRY, B.; SOUMONNI, E.; SANSONE, L. (org.). Africa, Brazil and the Construction of Transatlantic Black Identities. Trenton, NJ: Africa World Press, 2008, p. 19-43.

Recebido em: 14 de julho de 2018. Aprovado em: 20 de fevereiro de 2019. 